\title{
Cryptogenic Organizing Pneumonia
}

\author{
Vincent Cottin, M.D., Ph.D. ${ }^{1}$ Jean-François Cordier, M.D. ${ }^{1}$
}

${ }^{1}$ Hospices Civils de Lyon, Louis Pradel Hospital, National Reference Centre for Rare Pulmonary Diseases, Competence Centre for Pulmonary Hypertension, Department of Respiratory Medicine, University Claude Bernard Lyon I, University of Lyon, Lyon, France
Address for correspondence and reprint requests Vincent Cottin, M.D., Ph.D., Hôpital Louis Pradel, 28 avenue Doyen Lépine, F-69677 Lyon Cedex, France (e-mail: vincent.cottin@chu-lyon.fr).

Semin Respir Crit Care Med 2012;33:462-475.

\begin{abstract}
\section{Keywords}

- organizing pneumonia

- cryptogenic organizing pneumonia

- interstitial pneumonia

- disease

- connective tissue

Organizing pneumonia (OP) is a pathological pattern defined by the characteristic presence of buds of granulation tissue within the lumen of distal pulmonary airspaces consisting of fibroblasts and myofibroblasts intermixed with loose connective matrix. This pattern is the hallmark of a clinical pathological entity, namely cryptogenic organizing pneumonia (COP) when no cause or etiologic context is found. The process of intraalveolar organization results from a sequence of alveolar injury, alveolar deposition of fibrin, and colonization of fibrin with proliferating fibroblasts. A tremendous challenge for research is represented by the analysis of features that differentiate the reversible process of OP from that of fibroblastic foci driving irreversible fibrosis in usual interstitial pneumonia because they may determine the different outcomes of COP and idiopathic pulmonary fibrosis (IPF), respectively. Three main imaging patterns of COP have been described: (1) multiple patchy alveolar opacities (typical pattern), (2) solitary focal nodule or mass (focal pattern), and (3) diffuse infiltrative opacities, although several other uncommon patterns have been reported, especially the reversed halo sign (atoll sign). Definitive diagnosis is based on (1) a suggestive clinical radiological presentation, (2) the demonstration of the characteristic pathological pattern at lung histopathology, and (3) exclusion of possible causes. Transbronchial biopsies or a transthoracic biopsy may also contribute to the pathological diagnosis. Rapid clinical and imaging improvement is obtained with corticosteroid therapy. Because of the risk of misdiagnosing alternative conditions that may mimic OP, only typical cases may be managed without histopathological confirmation, and patients should be followed with particular attention paid to any clue of alternate diagnosis, especially in case of incomplete response to treatment. Patients and clinicians must be aware of frequent relapses after stopping corticosteroid treatment.
\end{abstract}

Organizing pneumonia (OP) is a pathological pattern defined by intraalveolar buds of granulation tissue consisting of fibroblasts and myofibroblasts intermixed with loose connective matrix, especially consisting of collagen (-Fig. 1). The pathological pattern of OP is the hallmark of a characteristic clinical pathological entity that may occur in the absence of etiology-cryptogenic OP (COP)-or as a result of a determined cause of inflammatory disorder such as connective tissue disease (secondary OP). Because buds of granulation tissue are present within the lumen of distal airspaces including the bronchioles, COP had been formerly referred to as bronchiolitis obliterans with organizing pneumonia (BOOP), a nomenclature now abandoned, because OP (and not bronchiolitis) is clearly the major lesion of COP. The term bronchiolitis obliterans was also a source of confusion with bronchiolitis with airflow obstruction occurring, for example, after lung or hematopoietic stem cell transplantation.
Issue Theme Orphan Lung Diseases; Guest Editor, Jay H. Ryu, M.D.
Copyright (c) 2012 by Thieme Medical Publishers, Inc., 333 Seventh Avenue, New York, NY 10001, USA. Tel: +1(212) 584-4662.
DOI http://dx.doi.org/ 10.1055/s-0032-1325157. ISSN 1069-3424. 

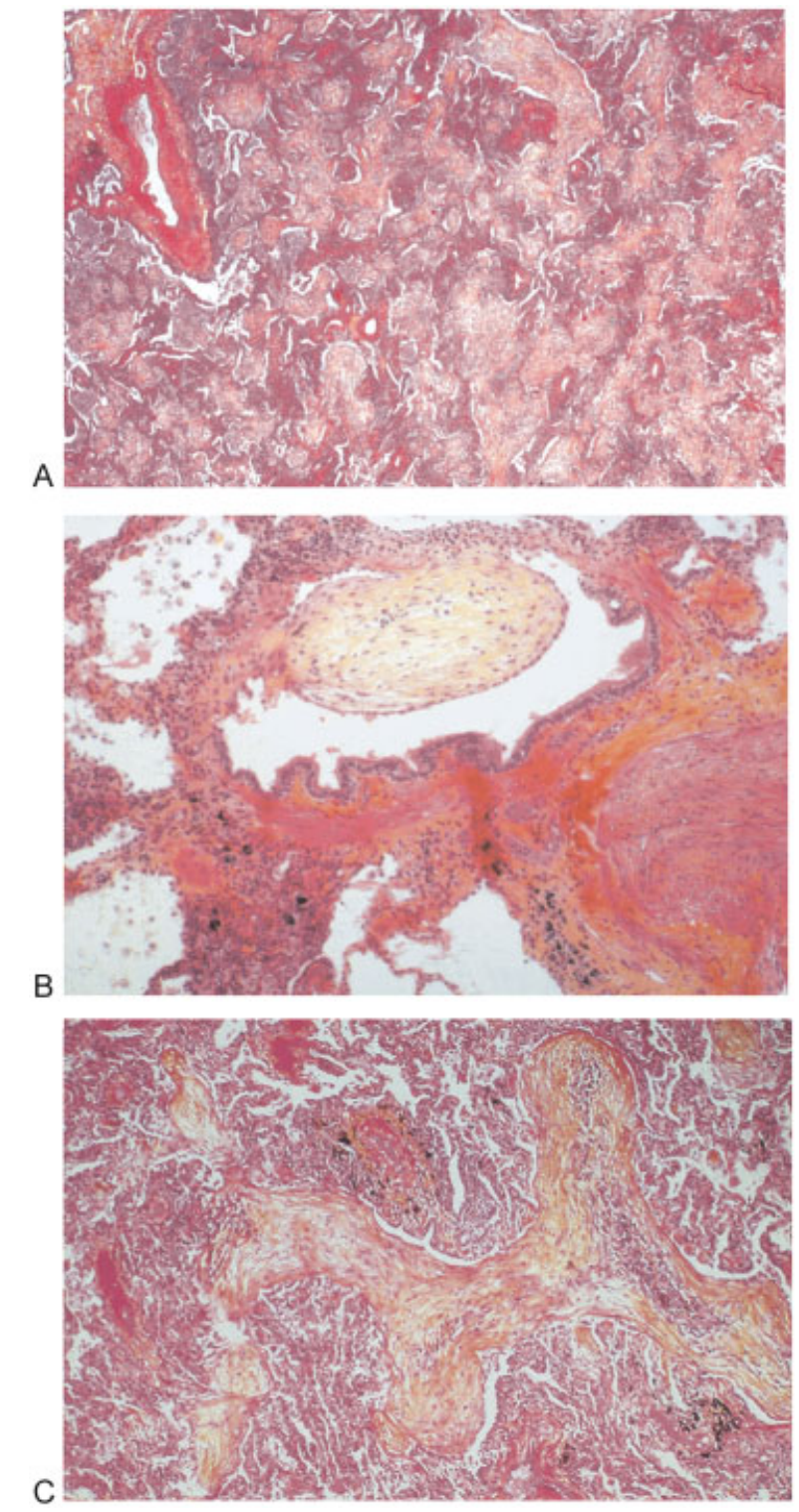

Figure 1 Photomicrograph of a lung biopsy in a patient with cryptogenic organizing pneumonia. (A) Typical organizing pattern with buds of granulation tissue in the distal air spaces $(40 \times)$. (B) Bud of granulation tissue in alveolar space and connected to the alveolar septum $(100 \times)$. (C) Extension of the granulation tissue from one alveolus to the next one through the interalveolar pores described by Kohn, so-called butterfly pattern $(100 \times)$. (Photographs courtesy of F. Thivolet-Béjui, M.D., Lyon, France.)

The first partial descriptions of OP can be traced back to the lectures from Charcot in 1877-78. ${ }^{1}$ Pathological observations published at the beginning of the $20^{\text {th }}$ century ${ }^{1}$ were mostly conducted during the autopsy of patients who had died from pneumococcal pneumonia before the era of antibiotic therapy. The initial intraalveolar material was described as consisting of fibrin, further colonized by fibroblasts and replaced by "fibrillated connective tissue," 1 a description close to the current definition. OP has then been considered as a characteristic pathological pattern resulting from organization of an inflammatory exudate in the lumen of alveoli of unresolved pneumonia, yet with only moderate clinical relevance. COP was eventually described in case reports, individualized as a clinicopathological entity without any evident cause in 1983 by Davison et al, ${ }^{2}$ then by several other series. ${ }^{3-6}$

Although it is not strictly interstitial, COP is included in the American Thoracic Society/European Respiratory Society international consensus classification of the idiopathic interstitial pneumonias ${ }^{7}$ because of its idiopathic nature and similarities that may occasionally tend to confuse COP (especially infiltrative forms of COP with progression to fibrosis) with interstitial pneumonias.

Although the epidemiology of COP is poorly known, the annual incidence of OP has been estimated to be 1.97/100 000 in the Icelandic population, with 1.10/100 000 and $0.87 / 100$ 000 for COP and for secondary OP, respectively. ${ }^{8}$

\section{Pathogenesis}

\section{Originality of Organizing Pneumonia as a Model}

OP is a unique model of an inflammatory lung disease with intraalveolar fibrosis that is completely reversible with therapy. Indeed, OP is characterized by intraalveolar accumulation of intermixed fibroblasts and connective matrix, especially collagen that is dramatically reversible with corticosteroids (CSs) contrary to other presentations of fibrosing lung disorders and especially that of idiopathic pulmonary fibrosis (IPF) with a pathological pattern of usual interstitial pneumonia (UIP). Although the buds of granulation tissue of OP and the fibroblastic foci of UIP share some morphological features, the outcome of the disease process clearly differs, a crucial difference that has been addressed in relatively few biopathological studies.

\section{Three Stages of Pathogenesis}

The pathogenesis of the pathological lesions of COP has been reported schematically to go through three stages ${ }^{1,9,10}$ :

1. The early stage (injury phase) is characterized by the flooding in the alveolar lumen of plasma proteins (permeability edema), with imbalance of the coagulation and fibrinolytic cascades in favor of the activation of the coagulation process, with further fibrin deposits, which are then populated by migrating inflammatory cells (lymphocytes, neutrophils, some eosinophils, and occasionally plasma cells and mast cells). Fibrin deposition may be prominent, as in the acute fibrinous variant of OP. The fibrillar material mostly consists of fibronectin, type III collagen, and proteoglycans, with a minority of type I collagen. Morphological and ultrastructural studies ${ }^{9,11}$ indicate the denudation of the epithelial basal laminae and extensive necrosis of alveolar epithelial type I cells, suggesting that alveolar epithelial injury forming gaps within the basal lamina may be the first event triggering this process. Capillary endothelial injury is often associated with epithelial lesions. Hyaline membranes are not found, in contrast to diffuse alveolar damage (DAD).

2. The second stage (proliferating phase) corresponds to the formation of fibroinflammatory buds. Fibrin is progressively fragmented by macrophages and inflammatory 
cells. Activated fibroblasts migrate through gaps of the basal lamina into the fragmented fibrin and inflammatory cells, where they proliferate, differentiate into myofibroblasts, and form cell clusters within the distal airspaces. Inflammatory cells and fibrin are progressively replaced by aggregated fibroblasts/myofibroblasts intermixed with a loose connective matrix tissue rich in collagen (especially collagen I), fibronectin, procollagen type III and proteoglycans. Alveolar epithelial cells proliferate, restoring the continuity of the alveolar capillary membrane and the integrity of the alveolar unit.

3. The third stage (mature phase) is characterized by "mature" fibrotic buds clearly delineated inside the alveolar space. Inflammatory cells and fibrin deposits are no longer found in alveolar buds, which are mostly constituted by typical myofibroblasts (with cytoplasmic filaments orientated toward the cell axis), ${ }^{9}$ organized in concentric rings alternating with layers of collagen bundles. At this stage the connective network consists of thin collagen-I fibers together with thinner fibrils of collagen and procollagen type III, and fibronectin.

4. In a fourth stage (resolution phase), this process resolves without significant sequelae, similar to reversible wound healing in the skin. The relative preservation of the alveolar basal laminae is considered to be required for the reversibility of the lesions.

\section{Comparison of Organizing Pneumonia to Fibroblastic Foci in Usual Interstitial Pneumonia}

Because OP is a reversible process and fibroblastic foci are considered to drive the irreversible fibrosing process in UIP, studies have aimed at comparing both types of lesions with the objective of identifying some of the key determinants of CS reversibility.

Proliferation of fibroblasts is comparable in the fibromyxoid lesions of COP and in fibroblastic foci of UIP; however, the rate of proliferation as measured by $\mathrm{K}_{\mathrm{i}}-67$ staining is much lower in both COP and UIP than in DAD. ${ }^{12}$ Conversely, the apoptotic activity is increased in intraalveolar buds of COP as compared with UIP. ${ }^{13}$ The soluble form of Fas is significantly increased in the bronchoalveolar lavage (BAL) fluid of patients with COP as compared with IPF. ${ }^{14}$ The expression of the members of the death receptors family tumor necrosis factor- $\alpha$ (TNF- $\alpha$ ) receptor- 1 and Fas by alveolar macrophages is higher in OP than in controls or patients with IPF. ${ }^{15}$ The serum marker of epithelial alveolar apoptosis M30 (measuring the caspase-cleaved cytokeratin-18 fragments) is higher in patients with COP than in UIP. ${ }^{16}$ Altogether, these observations suggest that a difference in the balance between proliferation and apoptosis might be involved in the distinct outcomes of these entities.

The process of alveolar reepithelialization seems to be disturbed or delayed in UIP, whereas it effectively contributes to alveolar integrity and resolution of pathological lesions in COP. The extent of reepithelialization of intraluminal connective tissue lesions is greater in COP than in UIP. ${ }^{17}$ Whereas regenerating epithelial cells of both COP and UIP are capable of synthesizing the laminin-5 $\gamma 2$ chain (needed for adhesive connections to the underlying basement membrane), ${ }^{17}$ the origin of regenerating cells is unknown in COP. Regenerating cells in UIP covering fibroblastic foci are organized in disordered layering and of variable morphology, and they express surfactant protein- $\mathrm{A}^{17}$ but not the tumor suppressor and inhibitor of angiogenesis ING4 (inhibitor of growth family member-4). ${ }^{18}$ In contrast, regenerating cells in COP, which are layered in an orderly fashion with a flat shape reminiscent of alveolar epithelial cells type 1 , express ING4 ${ }^{18}$ but not surfactant protein-A. ${ }^{17}$

Prominent capillarization is found in the newly formed intraalveolar fibromyxoid lesions in COP, reminiscent of the reversible granulation tissue in skin wound healing, ${ }^{19}$ in sharp contrast with fibroblastic foci in UIP where the vessels when present are found at the periphery of the lesion interfacing the interstitium. This angiogenic process may be mediated by the local production of vascular endothelial growth factor (VEGF) and its receptors Flt-1 and Flk-1, and basic fibroblast growth factor (bFGF), which are more strongly expressed in intraluminal fibromyxoid connective tissue of COP than in UIP. ${ }^{20}$

The pattern of matrix metalloproteinases (MMPs) expressed in OP is characterized by a predominance of MMP2 in BAL fluid and in tissues, ${ }^{21}$ in contrast with overproduction of MMP9 in UIP. However, elevated levels of MMP9 may also be found in the BAL fluid of patients with COP. ${ }^{22}$ Levels of the tissue inhibitor of MMPs (TIMP)-1 were also elevated in one study. $^{22}$

Overall, OP may be considered as a model of normal wound repair contrasting with the uncontrolled aberrant repair and fibrosing process observed in UIP/IPF. ${ }^{23}$

\section{From Animal Models to Human Observations}

Models of postinfectious OP have been developed in animals inoculated with viruses, namely the intranasal inoculation of moderate doses of reovirus serotype 1 in a susceptible strain of mice $(\mathrm{CBA} / \mathrm{J}),{ }^{24,25}$ the inoculation of Streptococcus pneumoniae in Wistar rats, ${ }^{26,27}$ the slow resolution of pneumonia due to Legionella pneumophila in Toll-like receptor-5-deficient mice, ${ }^{28}$ and the persistent lung infection of pigs with circovirus. ${ }^{29}$ These experimental observations strongly suggest that the genetic background may participate in the pathogenesis of OP, at least in animals, demonstrate the role of $\mathrm{T}$ cells, ${ }^{30,31}$ and indicate that the intensity of the initial epithelial injury (especially alveolar epithelial cells type 2) and yet undetermined factors inherent to the host may influence the evolution to either OP or DAD.

Fewer data regarding biopathology are available in patients with OP. Studies have demonstrated the involvement of $\mathrm{T}$ cells, ${ }^{32}$ the secretion of platelet-derived growth factor (PDGF), TNF- $\alpha$, and interleukin (IL)- 8 by alveolar macrophages $^{33,34}$; the presence in BAL fluid of monocyte chemotactic protein-1 (MCP-1), IL-10, IL-12, and IL-18 ${ }^{35}$; and the release of tryptase by mast cells. ${ }^{36}$

\section{Areas of Uncertainties}

The cellular origin of fibroblasts that populate the distal airspaces in COP is unclear. The respective contributions of proliferating lung fibroblasts, fibrocytes or bone-marrow- 
Table 1 High-Resolution Computed Tomographic Patterns in Organizing Pneumonia

\begin{tabular}{|c|c|}
\hline Typical pattern (most common) & Patchy alveolar opacities (typical COP) \\
\hline Less common patterns & $\begin{array}{l}\text { Solitary opacity (focal COP) } \\
\text { Infiltrative opacities (infiltrative COP) }\end{array}$ \\
\hline Rare patterns & $\begin{array}{l}\text { Reversed halo sign or atoll sign } \\
\text { Progressive fibrosis with reticulation and areas of consolidation } \\
\text { Multiple nodules } \\
\text { Multiple masses or nodules } \\
\text { Bronchocentric consolidation } \\
\text { Irregular lines or bands } \\
\text { Perilobular opacities }\end{array}$ \\
\hline
\end{tabular}

COP, cryptogenic organizing pneumonia.

derived fibroblasts, and epithelial-mesenchymal transition ${ }^{23}$ have not been evaluated in OP. The mechanism by which CSs facilitate the rapid resolution of OP is also unclear, although apoptosis is likely, ${ }^{25}$ with the cells concerned remaining to be identified.

Whether the pathophysiology of COP and secondary OP are comparable is also unknown. Although COP and secondary OP appear very similar, the microvascular density and the density of collagen fibers within intraalveolar airspaces may be higher in secondary OP than in COP.

\section{Clinical Features}

Clinical features are generally consistent in various series of COP. ${ }^{3-6,37-52}$ The mean age of onset of COP is $\sim 50$ to 60 years, with rare cases reported in children. ${ }^{53}$ There is no sex predisposition. COP is generally more common in nonsmokers or ex-smokers, especially in female patients. ${ }^{40}$ However, the frequency of the disease has not been adjusted for the prevalence of tobacco smoking in the different countries. More anecdotally, a seasonal relapse in early spring, ${ }^{54}$ and catamenial $\mathrm{OP}^{55}$ have been reported.

The initial manifestations are nonspecific, with the progressive onset of mild fever, cough, malaise, anorexia, weight loss, and progressive and usually mild dyspnea. Focal and sparse crackles are frequently found at auscultation over involved areas, with rarely clinical features of consolidation. Finger clubbing is absent. In most cases, the duration of onset is less than 3 months, with a subacute onset over a few weeks. The diagnosis is often delayed by 6 to 12 weeks, infectious pneumonia being the most common differential diagnosis, and in many cases the diagnosis is considered after the patients have received antibiotics. Dyspnea may occasionally be severe, especially in rapidly progressive forms of disease. Hemoptysis, ${ }^{56}$ chest pain, night sweats, and pneumothorax or pneumomediastinum $^{57,58}$ are rare. When present and prominent, arthralgias or myalgias should raise the suspicion of connective tissue disease (CTD). OP can be the inaugural manifestation of CTD. ${ }^{59}$

\section{Imaging Features}

Computed tomography (CT) of the chest is normal in less than $10 \%$ of cases. The imaging features of COP have been separated into three main characteristic patterns, namely multiple alveolar opacities (typical COP), solitary opacity (focal COP), and infiltrative opacities (infiltrative COP). ${ }^{4}$ In addition, COP may present with a variety of less common features on highresolution CT (HRCT) (- Table 1) shared with other diagnoses. $^{60-62}$

The most typical imaging pattern of COP consists of multiple patchy alveolar opacities ( $\mathbf{- F i g . ~} \mathbf{2}$ ), with a density ranging from ground glass to consolidation with air bronchograms. These are usually bilateral, with a subpleural distribution (-Fig. 3) and no predominant craniocaudal distribution. When migratory (i.e., with some opacities attenuating or clearing, while others appear in different areas), such multiple patchy alveolar opacities are so characteristic that they should immediately suggest the diagnosis of COP. Indeed, the correct diagnosis of COP could be made in 79\% of cases in a series of idiopathic interstitial pneumonia. ${ }^{63}$ The size of the opacities varies from 1 to $2 \mathrm{~cm}$ to lobar opacities. An air bronchogram is often present in consolidations that correspond pathologically to intraalveolar buds of granulation tissue within the distal airspaces. Patchy areas of ground-glass opacities are frequently observed, corresponding pathologically to the infiltration of alveolar wall by inflammatory cells with some OP in the distal airspaces. Small nodular opacities may be seen.

The second typical (yet less frequent) imaging pattern of COP is a solitary focal nodule or masslike area of consolidation. ${ }^{64-67}$ The diagnosis is most frequently obtained by surgical resection of a solitary asymptomatic lesion mimicking lung carcinoma, especially when associated with hypermetabolism on positron emission tomography, especially alveolar cell adenocarcinoma. Focal COP is often located in the upper lobes and likely represents nonresolving infectious pneumonia in most cases; however, recollection by patients of a history of respiratory infection is uncommon. ${ }^{4,41,58}$ An air bronchogram may be present, but it does not rule out the possibility of cancer. Focal COP can be differentiated from round atelectasis at imaging. ${ }^{66,68}$ Focal COP may regress spontaneously ${ }^{69}$ or with CS therapy and usually does not relapse after surgical excision or medical therapy.

The third imaging presentation of COP (infiltrative or progressive fibrotic COP) ${ }^{4}$ is characterized on HRCT by a mixed pattern of interstitial opacities associated with superimposed alveolar opacities, which may consist of a network of bowed 

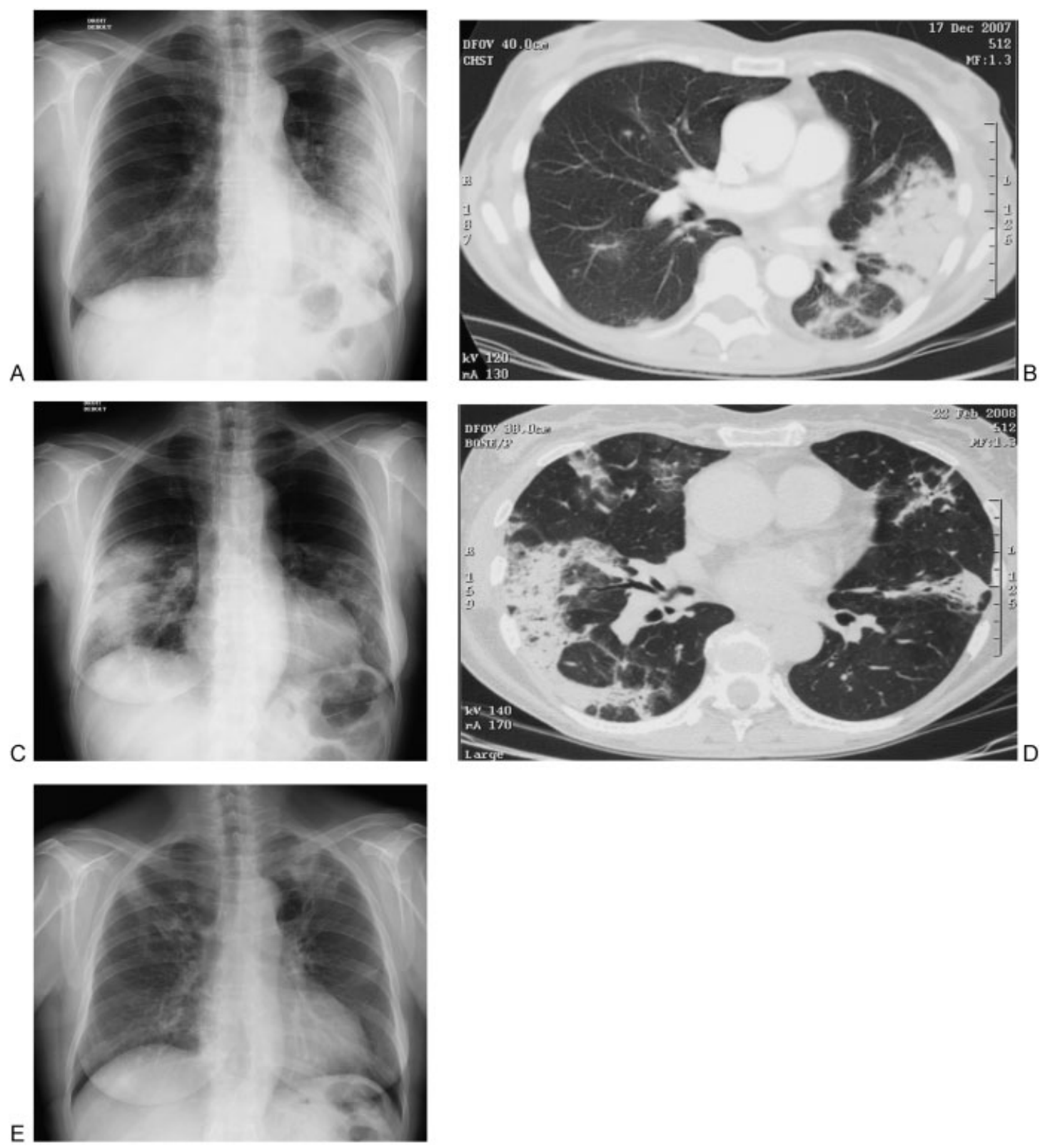

Figure 2 Chest imaging in a patient with cryptogenic organizing pneumonia (typical migrating pattern). (A) Chest radiograph and (B) chest computed tomographic (CT) scan at initial presentation showing alveolar peripheral opacities predominating in the left lung. (C) Chest radiograph and (D) chest CT 2 months later showing contralateral opacities. (E) Chest radiograph 6 months after initial presentation showing alveolar opacities in the upper lobes.

or polygonal opacities with poorly defined margins and bordering the interlobular septa ( - Fig. 4). ${ }^{70}$ Such pattern predominates in the lower lung zones. Honeycombing is not present. Although difficult to describe, this pattern may be recognized by the experienced clinician, especially in the context of OP associated with idiopathic inflammatory myopathy (with or without overt skin and/or muscle disease). ${ }^{71-73}$ The pathological correlate of these imaging features is often that of OP overlapping with idiopathic nonspecific interstitial pneumonia (NSIP), where the presence of associated OP in addition to interstitial cellular infiltration is common. This pattern is especially observed in the pulmonary manifestations of idiopathic inflammatory myopathy, which may precede the muscular manifestations.
Therefore autoantibodies associated with idiopathic inflammatory myopathy (especially antisynthetase antibodies) should be searched in all patients with infiltrative OP.

In addition to the classical imaging presentations of COP, a variety of other imaging features have been reported. ${ }^{61}$ The reversed halo sign or atoll sign, consisting of a circular consolidation pattern (corresponding pathologically to OP in the distal airspaces) surrounding an area of ground-glass opacities (corresponding to alveolar wall inflammation), has been considered highly suggestive of the diagnosis (-Fig. 5), ${ }^{74-76}$ especially in the absence of nodules that may be more frequently associated with tuberculosis. ${ }^{77}$ However, it can also be observed in a variety of other conditions, including tuberculosis, infectious pneumonia, paracoccidioidomycosis, 


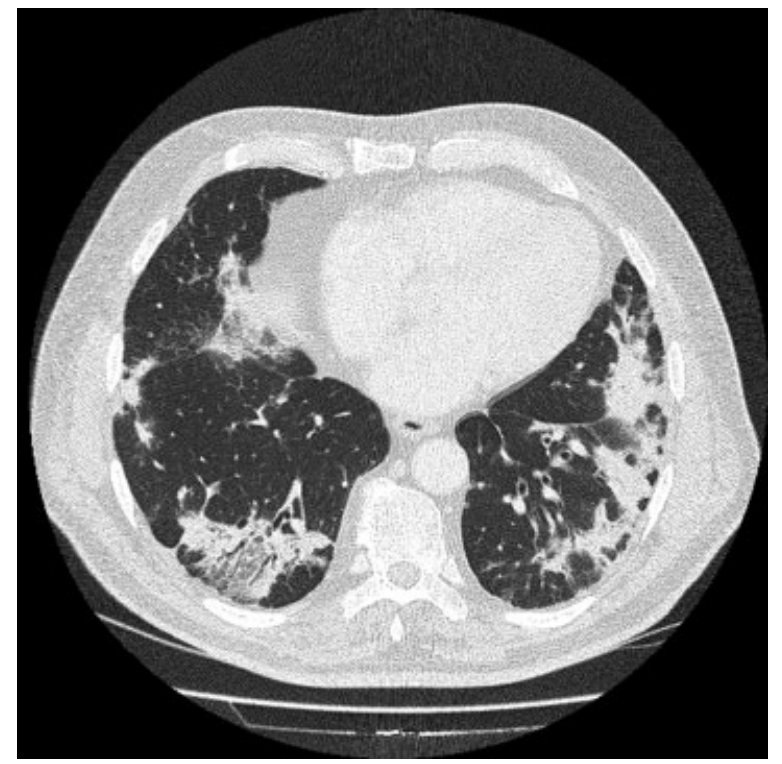

Figure 3 Computed tomographic scan of the chest in a patient with cryptogenic organizing pneumonia (typical pattern) demonstrating bilateral alveolar opacities (with peripheral predominance).

aspergillosis, alveolar cell adenocarcinoma, granulomatosis with polyangiitis (Wegener's), and pulmonary sarcoidosis. Several less common imaging presentations of COP have been occasionally reported. ${ }^{1,62}$ None of these patterns is specific enough to suggest the diagnosis of COP on imaging.

\section{Differential Diagnosis}

The main differential diagnosis of COP presenting with migratory alveolar opacities (-Table 2) is with idiopathic chronic eosinophilic pneumonia (CEP), which is associated with asthma in $75 \%$ of cases; the correct diagnosis of CEP is provided by blood eosinophilia usually $>1500 / \mathrm{mm}^{3}$ and

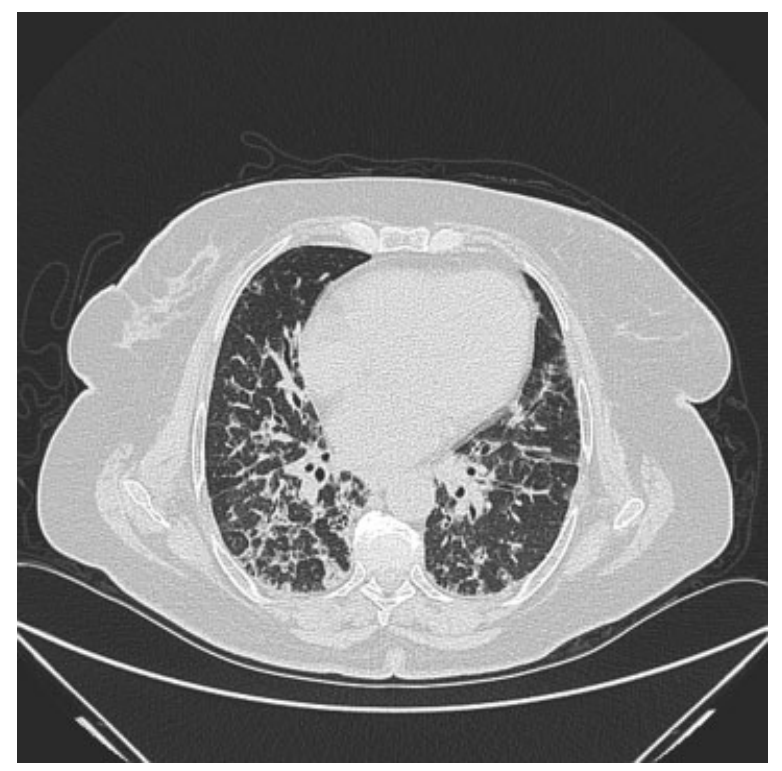

Figure 4 Computed tomographic scan of the chest in a patient with progressive/fibrosing cryptogenic organizing pneumonia showing diffuse infiltrative opacities.

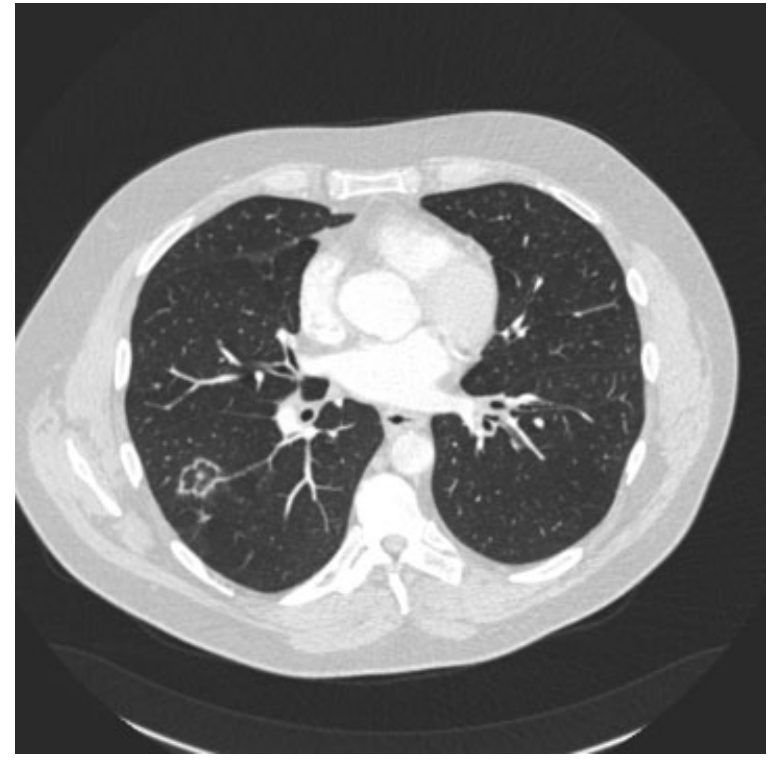

Figure 5 Computed tomographic scan of the chest in a patient with cryptogenic organizing pneumonia and reversed halo sign (atoll sign).

alveolar eosinophilia $>25 \%$ and often $>40 \%{ }^{78,79}$ However, some overlap is common between OP and CEP, ${ }^{64,80-84}$ with possible elevation of eosinophil cells in the BAL (usually mild) in patients with $\mathrm{COP}$, and conversely possible organization of the alveolar inflammatory exudate in CEP (less prominent than in COP). Both conditions also share a high frequency of relapse. Other conditions characterized by multiple alveolar opacities mostly include low-grade pulmonary lymphoma, and alveolar cell (pneumonic-type) adenocarcinoma, and rarely vasculitis, mycobacterial infection, or sarcoidosis.

Focal OP must be differentiated from primary lung cancer, metastatic lung tumor, lymphoma, and pulmonary infection. In patients with nonclassical imaging presentations of $\mathrm{COP}$, a wide range of alternate diagnoses can be discussed.

\section{Pulmonary Function Tests}

Lung function tests in COP show a mild to moderate restrictive ventilatory pattern and may occasionally be normal. ${ }^{3-6,37,46,47,54,85-88}$ The carbon monoxide transfer factor is generally reduced. The carbon monoxide transfer coefficient is usually normal. Hypoxemia is usually mild. More severe hypoxemia may be present in patients with diffuse infiltrative opacities (infiltrative COP). Furthermore, in some patients with typical COP, severe hypoxemia (usually well tolerated) may result from defective vasoconstriction and right-to-left shunting in perfused and nonventilated areas of lung consolidation, as demonstrated by increased alveolararterial oxygen difference while breathing $100 \%$ oxygen contrasting with negative contrast echocardiography ${ }^{89}$

\section{Biological Features}

Elevation of erythrocyte sedimentation rate, C-reactive protein serum level, ${ }^{83,90}$ and peripheral blood neutrophil count 
Table 2 Mimics of Organizing Pneumonia on Chest Imaging

\begin{tabular}{|l|l|}
\hline Multiple patchy alveolar opacities (typical COP) & $\begin{array}{l}\text { Eosinophilic pneumonia (especially chronic idiopathic) } \\
\text { Pneumonic-type alveolar cell adenocarcinoma of the lung } \\
\text { Primary pulmonary lymphoma (low-grade B cell lymphoma of the } \\
\text { mucosa-associated lymphoid tissue) }\end{array}$ \\
\begin{tabular}{|l} 
Aspiration pneumonia \\
Others: infectious pneumonia; tuberculosis or nontuberculous mycobacterial \\
infection; granulomatosis with polyangiitis (Wegener's); diffuse alveolar \\
hemorrhage; multiple infarction
\end{tabular} \\
\hline Solitary focal nodule or mass (focal COP) & $\begin{array}{l}\text { Lung carcinoma } \\
\text { Round pneumonia or abscess } \\
\text { Inflammatory pseudotumors } \\
\text { Others: all causes of coin lesions or masses }\end{array}$ \\
\hline $\begin{array}{l}\text { Diffuse infiltrative opacities (progressive/fi- } \\
\text { brosing COP) }\end{array}$ & $\begin{array}{l}\text { Idiopathic interstitial pneumonias, especially nonspecific interstitial } \\
\text { pneumonia and acute exacerbation of idiopathic pulmonary fibrosis } \\
\text { Interstitial pneumonias overlapping with organizing pneumonia } \\
\text { Others: all causes of infiltrative opacities especially of infectious or neoplastic } \\
\text { origin }\end{array}$ \\
\hline
\end{tabular}

COP, cryptogenic organizing pneumonia.

is common; however, these are nonspecific. There is no peripheral blood eosinophilia. Autoantibodies are usually negative.

The BAL differential cell count typically demonstrates a mixed pattern, consisting in increased percentage of lymphocytes (20 to $40 \%$ ), neutrophils ( $10 \%$ ), and possibly eosinophils ( $\sim 5 \%) .445,48,90-94$ The percentage of lymphocytes is usually higher than that of eosinophils in patients with COP but may be higher in cases overlapping with CEP. ${ }^{5,47,49,83,95}$ The presence of a small percentage of plasma cells or especially mast cells is remarkable. The $\mathrm{CD}^{+}: \mathrm{CD}^{+}$ratio of lymphocytes is usually decreased in the BAL but it does not contribute significantly to the diagnosis.

Because the BAL cell count does not establish the diagnosis of OP, its main role is to exclude other diagnoses and to contribute to search for possible causes. BAL cultures may demonstrate active infection. Cytological and immunocytological analysis of BAL may show the presence of low-grade lymphoma or alveolar cell carcinoma. The BAL also differentiates COP from CEP.

\section{Diagnosis}

The diagnosis of COP is based on (1) a clinical radiological presentation suggestive of $\mathrm{OP},(2)$ the demonstration of a pathological pattern of OP at histopathology of the lung, and (3) exclusion of possible causes of OP.

\section{Obtaining Lung Tissue}

Video-assisted thoracoscopy (VATS) is the method of choice to obtain lung tissue of sufficient size to evaluate the distribution of the lesions and the lung architecture. It is the most appropriate procedure to both definitely diagnose OP and exclude other processes. As in other idiopathic interstitial pneumonias, ${ }^{7}$ the lung biopsy should be performed in several lobes, be done before CSs are initiated, and be guided by preoperative CT of the chest, especially in cases of focal lesions. Although VATS is recommended for the definite histopathological diagnosis of OP, this invasive procedure is not always necessary, and a proportion of cases are managed empirically.

Transbronchial biopsies (TBBs) may be useful in patients with suspected COP and may obviate the need for VATS. ${ }^{1}$ Typical buds of granulation tissue may be observed on specimens of limited size and are characteristic enough to make a provisional diagnosis of OP in most cases. ${ }^{96,97}$ However, the sensitivity and specificity of TBBs for the diagnosis of OP have not been rigorously evaluated, and small specimens increase the risk of missing the central diagnosis. Because their small size does not allow exclusion of other histopathological processes coexisting with foci of OP, informative TBBs should be considered diagnostic of OP only in patients with a typical clinical and imaging profile. The diagnosis must be reconsidered in case of unexpected evolution, especially lack of complete resolution under CS therapy.

Core needle biopsy is generally safe and may be appropriate in a minority of patients with suspected OP, ${ }^{98-101}$ especially with focal consolidation at imaging. Lung specimens obtained by core needle biopsy are much larger than TBBs, and these may allow a more confident pathological diagnosis. However, published experience of this diagnostic method is limited. Microbiological analysis should also be performed on the lung specimen.

Overall, fiberoptic bronchoscopy (which excludes any bronchial obstruction) with BAL (including differential cell count and cultures) is recommended in any patient in whom COP is suspected. When bronchoscopy is performed, TBBs should be considered. The association of a typical clinical radiological pattern and a mixed lymphocytic pattern at BAL differential cell count, such as a marked increase in lymphocytes ( $\sim 40 \%$ ) and a mild increase in neutrophils ( $\sim 4$ to $10 \%$ ) and eosinophils ( $\sim 1$ to $5 \%$ ) is considered highly suggestive of $\mathrm{OP}$ (and of COP in the appropriate clinical context). VATS lung biopsy is considered if a pathological diagnosis of OP has not been obtained. The role of a core needle biopsy in this setting has not been established, and it may be used as a less invasive 
procedure in patients with comorbidities or those who decline thoracoscopy. When the lung biopsy is available, the diagnosis of COP should be eventually established through multidisciplinary discussion involving the clinician, radiologist, pathologist, and thoracic surgeon ${ }^{7}$ in atypical cases. However, in most cases the pathological diagnosis of OP is straightforward. Such a multidisciplinary approach is particularly useful in cases of COP with pathological features overlapping with CEP, NSIP, or DAD.

\section{Histopathological Diagnosis of Organizing Pneumonia} When performed, histopathological analysis of the lung biopsy demonstrates buds of granulation tissue consisting of fibroblasts and myofibroblasts embedded in connective tissue, ${ }^{7,102,103}$ which are the hallmark of OP. One typical pathological feature of OP is the extension of the granulation tissue from one alveolus to the next one through the interalveolar pores described by Kohn, ${ }^{1}$ the so-called butterfly pattern. ${ }^{10}$ Although predominantly involving the alveoli, the granulation tissue often extends to adjacent bronchioli, the lumen of which is obstructed, hence the now abandoned terminology of BOOP. The overall architecture of the lung is preserved. Mild infiltration of the alveolar interstitium by inflammatory cells may be present. Foamy alveolar macrophages are often found in areas where alveoli are not filled with granulation tissue.

Outside the areas of the lung involved by OP, the histology of the lung is normal or characterized by mild inflammation. Additional findings suggestive of another diagnosis in secondary OP include necrosis or microabscesses (infectious process, necrotizing vasculitis) and organic debris (occult aspiration pneumonia). Special stains for microorganisms may be useful.

\section{Differential Pathological Diagnosis of Organizing Pneumonia}

In cases with prominent fibrin deposition, with hyperplasia of type II pneumocytes, and moderate associated foci of $\mathrm{OP}$, the pathological diagnosis of acute fibrinous OP may be made, ${ }^{104}$ especially in patients with rapidly progressive disease or acute respiratory failure. Furthermore, careful examination of the lung biopsy must be conducted to rule out other histological features that may suggest other conditions associated with OP. Although slight differences can be found by morphometry between lesions of COP and those of secondary OP (regarding collagen fiber density, myofibroblast proliferation, microvascular density, and endothelial activity), ${ }^{105}$ histopathology cannot differentiate between idiopathic and nonidiopathic cases. Moreover, some areas of intraalveolar organization can be present nonspecifically as an accessory finding in a variety of conditions other than OP, especially nonresolving infectious pneumonia. ${ }^{106}$ For example, some foci of OP can be found in more than half of the cases diagnosed with granulomatosis with polyangiitis ( Wegener's), ${ }^{107-109}$ and may be observed in NSIP, CEP, ${ }^{79}$ hypersensitivity pneumonitis, ${ }^{110,111}$ chronic pneumonia distal to bronchial obstruction (including especially lung cancer), abscesses, cystic fibrosis, ${ }^{112}$ pneumoconiosis, ${ }^{113}$ the organizing phase of DAD, ${ }^{7}$ or adjacent to pleural plaques. ${ }^{114}$ Therefore the pathological diagnosis of OP must be made only in those cases where intraalveolar organization is the predominant pattern, and assessing the significance of OP may be difficult in small biopsy specimen.

\section{Management in the Absence of a Lung Biopsy}

A reasonable alternative to lung biopsy is represented by patient management in the absence of confirmation of the histopathology of OP, an approach commonly used in the community. Because of the risk of misdiagnosing alternative conditions that may mimic OP, only typical cases at imaging (e.g., multiple patchy consolidation) with compatible clinical and BAL features should be treated without biopsy. Patients must be informed that the diagnosis is only probable, and that careful follow-up is necessary. Furthermore, particular attention must be paid to any clue of alternate diagnosis, including peripheral blood or BAL eosinophilia, microbiology of BAL, and especially unusual evolution (e.g., incomplete response to CSs or relapse despite $>20 \mathrm{mg} / \mathrm{d}$ of oral prednisone). In patients receiving CS therapy for probable COP in the absence of histopathological confirmation, rapid improvement is often considered to reinforce the diagnosis of OP, although it is not specific (as similar improvement can occur with CSs in CEP).

\section{Exclusion of Possible Causes}

The approach to patients with OP (be it established by biopsy or diagnosed without) must include a careful clinical history and inquiry for infections (- Table 3), drugs (-Table 4), and the presence of comorbid diseases (-Table 5) such as CTD (including formes frustes of, or undifferentiated CTD), cancer, thoracic radiotherapy for breast cancer, exposure to drugs, inflammatory bowel disease, aspiration, or less common conditions such as common variable immune deficiency or toxic exposures (e.g., titanium nanoparticles, acetic acid). ${ }^{1,115,116}$ Because the clinical, laboratory, and imaging features and outcome of secondary OP generally parallel those of $\mathrm{COP},{ }^{117,118}$ a careful etiologic inquiry is necessary in any OP without evident cause and especially in case of relapsing OP.

A histopathology of OP especially prompts a search for infectious agents; however, the infection is no longer active at the time of OP, and the diagnosis of the infection may be based on the clinical history, the rise of antibody titers against the infectious agent, or occasionally on the direct identification of the infectious agent on pathology. All drugs taken in the weeks or months preceding the symptoms must be systematically recorded. ${ }^{119}$ Radiation therapy to the breast after tumorectomy for cancer may precipitate the development of OP in $\sim 2.5 \%$ of treated women and a mean delay of 3 to 6 months after the completion of irradiation. ${ }^{120}$ Radiationinduced OP clearly differs from radiation pneumonitis because it may involve nonirradiated areas of the lung, may be migratory, and rapidly clears with CS therapy (while radiation pneumonitis is limited to the radiation field and results in retractile consolidation with traction bronchiectasis). Among the group of connective tissue diseases, OP occurs mainly in 
Table 3 Main Infectious Agents That Cause Organizing Pneumonia

\begin{tabular}{|l|l|}
\hline Bacteria & Streptococcus pneumoniae \\
& Actinomyces israelii \\
& Chlamydia pneumoniae \\
& Coxiella burnetii \\
& Legionella pneumophila \\
& Mycoplasma pneumonia \\
& Nocardia asteroides \\
& Staphylococcus aureus \\
& Serratia marcescens \\
& Pseudomonas aeruginosa \\
\hline Viruses & Human immunodeficiency virus \\
& Influenza virus \\
& Parainfluenza virus \\
& Herpesvirus \\
& Hepatitis C virus \\
\hline Parasites & Plasmodium vivax \\
\hline Fungi & Cryptococcus neoformans \\
& Penicillium janthinellum \\
& Pneumocystis jiroveci (in AIDS) \\
\hline
\end{tabular}

dermatomyositis or polymyositis (with frequent overlapping features with NSIP) ${ }^{121,122}$ and in rheumatoid arthritis, ${ }^{123}$ and occasionally precedes the development of the CTD.

One common and recently emphasized cause of OP is aspiration pneumonia. ${ }^{124,125}$ OP is a frequent pathological feature in patients with occult aspiration pneumonia related to food or other particulate matter. Aspiration pneumonia seems to be a more frequent cause of OP than previously suspected. Because it is evident clinically in only $<10 \%$ of case, predisposing factors for aspiration should be sought (e.g., esophageal or gastric causes, drug use, neurological conditions). The presence of multinucleated giant cells, acute bronchopneumonia or bronchiolitis, or suppurative granulomas in a background of OP should prompt the pathologist to look for foreign material and particulate matters on the lung biopsy, and the clinician to evaluate for possible aspiration.

Table 4 Main Drugs That Cause Organizing Pneumonia

\begin{tabular}{|l|l|}
\hline 5-aminosalicylic acid & Minocycline \\
\hline Amiodarone & Nilutamide \\
\hline Amphotericin B & Nitrofurantoin \\
\hline Beta-blockers & Penicillamine \\
\hline Bleomycin & Phenytoin \\
\hline Busulfan & Statins \\
\hline Carbamazepine & Rituximab \\
\hline Dihydroergocryptin & Sirolimus \\
\hline Everolimus & Sulfasalazine \\
\hline Interferon- $\alpha$ & Tacrolimus \\
\hline Interferon- $\beta$ & Thalidomide \\
\hline Mesalazine & Tocilizumab \\
\hline Methotrexate & Trastuzumab \\
\hline
\end{tabular}

For a complete list, visit www.pneumotox.com.
Table 5 Miscellaneous Causes and Clinical Settings Associated with Organizing Pneumonia

\begin{tabular}{|l|l|}
\hline $\begin{array}{l}\text { Identified } \\
\text { causes }\end{array}$ & $\begin{array}{l}\text { Infections (see }- \text { Table 3) } \\
\text { Drugs (see - Table 4) } \\
\text { Distal to airways obstruction } \\
\text { Fumes and toxic exposures (e.g., aerosolized } \\
\text { textile dye Acramin FWN; mustard gas) }\end{array}$ \\
\hline clinical & $\begin{array}{l}\text { Occult aspiration pneumonia } \\
\text { Connective tissue disease } \\
\text { Primary biliary cirrhosis } \\
\text { Inflammatory bowel diseases (ulcerative colitis; } \\
\text { Crohn disease) } \\
\text { Transplantation (lung, liver), bone marrow graft } \\
\text { Hematologic malignancies (leukemias, } \\
\text { myeloblastic, lymphoblastic myelomonocytic, } \\
\text { T cell; Hodgkin disease) } \\
\text { Cancers and postthoracic radiotherapy, espe- } \\
\text { cially for breast cancer } \\
\text { Hypersensitivity pneumonitis } \\
\text { Eosinophilic pneumonia } \\
\text { Chronic bronchiolitis } \\
\text { Others: common variable immune deficiency, } \\
\text { Sweet syndrome, polymyalgia rheumatica, Beh- } \\
\text { çet disease, thyroid diseases, vasculitis, } \\
\text { sarcoidosis }\end{array}$ \\
\hline
\end{tabular}

\section{Treatment}

\section{Corticosteroid Treatment}

CS treatment represents the standard therapy in COP. Initiation of therapy results in dramatic clinical improvement in typical COP, with regression of symptoms within days. Imaging improves rapidly, with consolidation evolving to ground glass and eventually regressing completely within a month without significant sequelae. ${ }^{60}$ The overall prognosis of typical COP is excellent ${ }^{48}$ (whereas the outcome is less favorable in patients with secondary $\mathrm{OP}^{41}$ ). Patients with airspace opacities at imaging have a particularly good outcome. The less frequent linear or reticular opacities may not resolve. Presence of interstitial fibrosis at pathology ${ }^{126}$ or of septal thickening and remodeling at $\mathrm{CT}^{127}$ is associated with persistent disease.

The doses and duration of CS treatment have not been established, and treatment should aim at the optimal balance between disease control and side effects. In the past, the initial doses of prednisone have varied from 0.75 to $1.5 \mathrm{mg} /$ $\mathrm{kg} / \mathrm{d} .{ }^{40,48}$ Because response to CS is dramatic in most cases, the current approach is to avoid intense and prolonged CS treatment, to limit the risk of iatrogenic complications. We therefore start with prednisone, $0.75 \mathrm{mg} / \mathrm{kg} / \mathrm{d}$ for 4 weeks, then progressively decrease for a total duration of treatment of 24 weeks (-Table 6). We now tend to use a shorter treatment protocol, starting with $0.75 \mathrm{mg} / \mathrm{kg} / \mathrm{d}$ of prednisone and tapered over a total of 12 weeks, possibly associated with clarithromycin. Other treatment protocols with slower decrease of therapy have been proposed. High-dose intravenous methylprednisolone is often used as initial therapy in patients with rapidly progressive COP. Spontaneous improvement over 3 to 6 months has been reported in $\mathrm{COP}^{3,128}$; 
Table 6 Proposed Therapeutic Regimen for Typical Cryptogenic Organizing Pneumonia

\begin{tabular}{|l|l|l|}
\hline Step & Duration (weeks) & Doses of Prednisone \\
\hline \multicolumn{3}{|l|}{ Treatment of initial episode } \\
\hline 1 & 4 & $0.75 \mathrm{mg} / \mathrm{kg} / \mathrm{d}$ \\
\hline 2 & 4 & $0.5 \mathrm{mg} / \mathrm{kg} / \mathrm{d}$ \\
\hline 3 & 4 & $20 \mathrm{mg} / \mathrm{d}$ \\
\hline 4 & 6 & $10 \mathrm{mg} / \mathrm{d}$ \\
\hline 5 & 6 & $5 \mathrm{mg} / \mathrm{d}$ \\
\hline \multicolumn{2}{|l|}{ Treatment of relapse } & $20 \mathrm{mg} / \mathrm{d}$ \\
\hline 1 & 12 & $10 \mathrm{mg} / \mathrm{d}$ \\
\hline 2 & 6 & $5 \mathrm{mg} / \mathrm{d}$ \\
\hline 3 & 6 &
\end{tabular}

however, clinical monitoring without therapy is not recommended except in patients with no symptoms or mild radiographic findings. ${ }^{129}$

Focal COP does not require CS therapy after surgical resection of the lesion (performed for suspicion of lung cancer). ${ }^{4,41,130}$ Secondary OP requires treatment of the underlying condition (CTD, infection) or withdrawal of the causative drug or exposure, ${ }^{41}$ and may require a shorter treatment if the offending agent has been withdrawn. ${ }^{131}$

\section{Immunosuppressive Therapy}

Although most cases of typical COP with alveolar consolidation have a rapid favorable outcome with CS therapy, a minority of patients have persistent disease, especially those with reticulation on HRCT or with the fibrosing/progressive variant of COP. In this situation, cyclophosphamide or azathioprine may be used as an adjunct to CS therapy, which is usually continued at a low dose $(\sim 0.25 \mathrm{mg} / \mathrm{kg} / \mathrm{d}$ of oral prednisone). ${ }^{132}$ However, the possible benefit of immunosuppressive therapy has not been evaluated.

\section{Management of Relapses}

Relapse occurs in 13 to $58 \%$ of patients with COP on decreasing or after stopping CS, ${ }^{40,41}$ and $\sim 20 \%$ of patients experience more than one episode of relapse. ${ }^{40}$ Delayed treatment, mild cholestasis, ${ }^{40}$ and severe hypoxemia ${ }^{133}$ have been reported to be associated with a higher risk of relapse. Relapses are not associated with increased morbidity or mortality. Dramatic response to resumed therapy is observed in most cases, and doses of $20 \mathrm{mg}$ per day of prednisone (with progressive decrease) suffice to treat the relapse in most cases. Importantly, any relapse should prompt a search for a persisting cause of OP, especially drug intake. Relapses occurring while receiving more than 15 to $30 \mathrm{mg}$ of prednisone per day (depending on body weight) should prompt extensive reappraisal of the diagnosis (especially the search for a cause) and clinical-radiological-pathological discussion, especially when a large sample is not available for histopathology.

\section{Macrolides}

Macrolides have been suggested for their antiinflammatory properties as an alternative option in patients who are intolerant of CSs or who frequently relapse. ${ }^{134}$ However, the effect of macrolide therapy has been reported in fewer than 50 patients, including a majority with COP and some with secondary OP especially radiation-induced OP. ${ }^{134-139}$ Therapy consisted of erythromycin at a dose of $600 \mathrm{mg}$ daily for 3 to 4 months, ${ }^{136}$ clarithromycin $500 \mathrm{mg}$ twice daily, or azithromycin. ${ }^{129,134}$ Tolerance and safety of macrolides were generally good. The response rate of patients receiving macrolide therapy and the potential influence of macrolides on long-term outcome of COP cannot be assessed, and conclusions are limited by the observational design and heterogeneity of studies and by reporting bias. Thus the available evidence does not support the use of macrolide therapy in patients with COP. In addition, the benefit initially observed in case reports is not confirmed by the empirical routine use of these drugs.

\section{Variants of Organizing Pneumonia}

\section{Fibrosing Variant of Organizing Pneumonia (Severe Organizing Pneumonia)}

Cases of COP have been reported that do not completely resolve and have the potential to cause severe or fulminant respiratory failure requiring mechanical ventilation, occasionally leading to death. ${ }^{140}$ Such cases only exceptionally correspond to genuine OP pathological lesions, and are characterized by residual or progressive interstitial fibrosis associated with OP lesions.,41,127,140 These cases may correspond to an overlap between OP and interstitial fibrosis as described in seven of 16 patients who had a clinical and histological diagnosis of COP. ${ }^{4}$ In patients with acute exacerbation of IPF, features of DAD or OP are found in association with preexisting UIP. ${ }^{141}$ Such cases may also represent overlap of COP with acute respiratory distress syndrome with pathological features of DAD undergoing organization, ${ }^{141}$ fibrotic NSIP, ${ }^{142}$ or acute fibrinous OP. ${ }^{104}$

In such cases, the response to CS is not as favorable as in classical COP. Immunosuppressive agents (especially cyclophosphamide) are usually added to CSs (often used at a higher dose, starting with 1 to $2 \mathrm{mg} / \mathrm{kg} / \mathrm{d}$ of intravenous methylprednisolone) with variable outcome.

\section{Acute Fibrinous Organizing Pneumonia}

Acute fibrinous OP is a histopathological pattern first reported in patients with acute respiratory failure, with predominantly basal and bilateral areas of consolidation at imaging. It is characterized histologically by abundant fibrin deposition within the alveolar airspaces, with hyperplasia of type II pneumocytes, associated OP, and absence of hyaline membranes (which are the hallmark of DAD). ${ }^{104}$ One case of acute fibrinous OP presenting as a localized mass has been reported. ${ }^{143}$ Acute fibrinous OP is currently considered a pathological variant of OP that may be associated with a more rapidly progressing disease. Similarly to OP, it may be 
encountered in the context of various underlying conditions, including infection, eosinophilic pneumonia, or vasculitis, or in the surrounding of pulmonary infarction.

Of note, other conditions usually considered as variants of OP have been reported, including bronchiolitis with interstitial pneumonitis ${ }^{144,145}$ and bronchiolitis-peribronchiolar OP. $^{146}$

\section{References}

1 Cordier JF. Cryptogenic organising pneumonia. Eur Respir J 2006;28(2):422-446

2 Davison AG, Heard BE, McAllister WAC, Turner-Warwick ME. Cryptogenic organizing pneumonitis. QJ Med 1983;207:382-394

3 Epler GR, Colby TV, McLoud TC, Carrington CB, Gaensler EA. Bronchiolitis obliterans organizing pneumonia. N Engl J Med 1985;312(3):152-158

4 Cordier JF, Loire R, Brune J. Idiopathic bronchiolitis obliterans organizing pneumonia. Definition of characteristic clinical profiles in a series of 16 patients. Chest 1989;96(5):9991004

5 Bartter T, Irwin RS, Nash G, Balikian JP, Hollingsworth HH. Idiopathic bronchiolitis obliterans organizing pneumonia with peripheral infiltrates on chest roentgenogram. Arch Intern Med 1989;149(2):273-279

6 Guerry-Force ML, Müller NL, Wright JL, et al. A comparison of bronchiolitis obliterans with organizing pneumonia, usual interstitial pneumonia, and small airways disease. Am Rev Respir Dis 1987;135(3):705-712

7 American Thoracic Society; European Respiratory Society. American Thoracic Society/European Respiratory Society International Multidisciplinary Consensus Classification of the Idiopathic Interstitial Pneumonias. This joint statement of the American Thoracic Society (ATS), and the European Respiratory Society (ERS) was adopted by the ATS board of directors, June 2001 and by the ERS Executive Committee, June 2001. Am J Respir Crit Care Med 2002;(2):165:277-304

8 Gudmundsson G, Sveinsson O, Isaksson HJ, Jonsson S, Frodadottir $\mathrm{H}$, Aspelund T. Epidemiology of organising pneumonia in Iceland. Thorax 2006;61(9):805-808

9 Peyrol S, Cordier JF, Grimaud JA. Intra-alveolar fibrosis of idiopathic bronchiolitis obliterans-organizing pneumonia. Cell-matrix patterns. Am J Pathol 1990;137(1):155-170

10 Cordier JF, Peyrol S, Loire R. Bronchiolitis obliterans organizing pneumonia as a model of inflammatory lung disease. In: Epler G, ed. Diseases of the Bronchioles. New York: Raven Press; 1994:313-345

11 Myers JL, Katzenstein AL. Ultrastructural evidence of alveolar epithelial injury in idiopathic bronchiolitis obliterans-organizing pneumonia. Am J Pathol 1988;132(1):102-109

12 El-Zammar O, Rosenbaum P, Katzenstein A-LA. Proliferative activity in fibrosing lung diseases: a comparative study of $\mathrm{Ki}$ 67 immunoreactivity in diffuse alveolar damage, bronchiolitis obliterans-organizing pneumonia, and usual interstitial pneumonia. Hum Pathol 2009;40(8):1182-1188

13 Lappi-Blanco E, Soini Y, Pääkkö P. Apoptotic activity is increased in the newly formed fibromyxoid connective tissue in bronchiolitis obliterans organizing pneumonia. Lung 1999;177(6): 367-376

14 Kuwano K, Kawasaki M, Maeyama T, et al. Soluble form of fas and fas ligand in BAL fluid from patients with pulmonary fibrosis and bronchiolitis obliterans organizing pneumonia. Chest 2000;118 (2):451-458

15 Ye Q Dai H, Sarria R, Guzman J, Costabel U. Increased expression of tumor necrosis factor receptors in cryptogenic organizing pneumonia. Respir Med 2011;105(2):292-297
16 Chung WY, Sun JS, Park JH, et al. Epithelial apoptosis as a clinical marker in idiopathic interstitial pneumonia. Respir Med 2010;104(11):1722-1728

17 Lappi-Blanco E, Kaarteenaho-Wiik R, Salo S, et al. Laminin-5 gamma2 chain in cryptogenic organizing pneumonia and idiopathic pulmonary fibrosis. Am J Respir Crit Care Med 2004; 169(1):27-33

18 Tzouvelekis A, Aidinis V, Harokopos V, et al. Down-regulation of the inhibitor of growth family member 4 (ING4) in different forms of pulmonary fibrosis. Respir Res 2009;10:14

19 Lappi-Blanco E, Kaarteenaho-Wiik R, Soini Y, Risteli J, Pääkkö P. Intraluminal fibromyxoid lesions in bronchiolitis obliterans organizing pneumonia are highly capillarized. Hum Pathol 1999; 30(10):1192-1196

20 Lappi-Blanco E, Soini Y, Kinnula V, Pääkkö P. VEGF and bFGF are highly expressed in intraluminal fibromyxoid lesions in bronchiolitis obliterans organizing pneumonia. J Pathol 2002;196 (2):220-227

21 Suga M, Iyonaga K, Okamoto T, et al. Characteristic elevation of matrix metalloproteinase activity in idiopathic interstitial pneumonias. Am J Respir Crit Care Med 2000;162(5):1949-1956

22 Choi KH, Lee HB, Jeong MY, et al. The role of matrix metalloproteinase- 9 and tissue inhibitor of metalloproteinase- 1 in cryptogenic organizing pneumonia. Chest 2002;121(5): 1478-1485

23 Wynn TA. Integrating mechanisms of pulmonary fibrosis. J Exp Med 2011;208(7):1339-1350

24 Bellum SC, Dove D, Harley RA, et al. Respiratory reovirus 1/L induction of intraluminal fibrosis. A model for the study of bronchiolitis obliterans organizing pneumonia. Am J Pathol 1997;150(6):2243-2254

25 Lopez AD, Avasarala S, Grewal S, Murali AK, London L. Differential role of the Fas/Fas ligand apoptotic pathway in inflammation and lung fibrosis associated with reovirus $1 / \mathrm{L}$-induced bronchiolitis obliterans organizing pneumonia and acute respiratory distress syndrome. J Immunol 2009;183(12):8244-8257

26 Rhodes GC, Lykke AW, Tapsall JW, Smith LW. Abnormal alveolar epithelial repair associated with failure of resolution in experimental streptococcal pneumonia. J Pathol 1989;159(3):245-253

27 Rhodes GC, Tapsall JW, Lykke AW. Alveolar epithelial responses in experimental streptococcal pneumonia. J Pathol 1989;157(4): 347-357

28 Hawn TR, Berrington WR, Smith IA, et al. Altered inflammatory responses in TLR5-deficient mice infected with Legionella pneumophila. J Immunol 2007;179(10):6981-6987

29 Cheng CC, Lee YF, Lin NN, Wu CL, Tung KC, Chiu YT. Bronchiolitis obliterans organizing pneumonia in Swine associated with porcine circovirus type 2 infection. J Biomed Biotechnol 2011; 2011:245728

30 Majeski EI, Harley RA, Bellum SC, London SD, London L. Differential role for $\mathrm{T}$ cells in the development of fibrotic lesions associated with reovirus $1 / \mathrm{L}$-induced bronchiolitis obliterans organizing pneumonia versus Acute Respiratory Distress Syndrome. Am J Respir Cell Mol Biol 2003;28(2):208-217

31 Majeski EI, Paintlia MK, Lopez AD, Harley RA, London SD, London L. Respiratory reovirus $1 / \mathrm{L}$ induction of intraluminal fibrosis, a model of bronchiolitis obliterans organizing pneumonia, is dependent on $\mathrm{T}$ lymphocytes. Am J Pathol 2003;163(4): 1467-1479

32 Mukae H, Kadota J, Kohno S, Matsukura S, Hara K. Increase of activated T-cells in BAL fluid of Japanese patients with bronchiolitis obliterans organizing pneumonia and chronic eosinophilic pneumonia. Chest 1995;108(1):123-128

33 Aubert JD, Paré PD, Hogg JC, Hayashi S. Platelet-derived growth factor in bronchiolitis obliterans-organizing pneumonia. Am J Respir Crit Care Med 1997;155(2):676-681

34 Carré PC, King TE Jr, Mortensen R, Riches DW. Cryptogenic organizing pneumonia: increased expression of interleukin-8 
and fibronectin genes by alveolar macrophages. Am J Respir Cell Mol Biol 1994;10(1):100-105

35 Forlani S, Ratta L, Bulgheroni A, et al. Cytokine profile of bronchoalveolar lavage in BOOP and UIP. Sarcoidosis Vasc Diffuse Lung Dis 2002;19(1):47-53

36 Pesci A, Majori M, Piccoli ML, et al. Mast cells in bronchiolitis obliterans organizing pneumonia. Mast cell hyperplasia and evidence for extracellular release of tryptase. Chest 1996; 110(2):383-391

37 Davison AG, Heard BE, McAllister WAC, Turner-Warwick ME. Cryptogenic organizing pneumonitis. Q J Med 1983;52(207): 382-394

38 Cazzato S, Zompatori M, Baruzzi G, et al. Bronchiolitis obliteransorganizing pneumonia: an Italian experience. Respir Med 2000;94(7):702-708

39 Chang J, Han J, Kim DW, et al. Bronchiolitis obliterans organizing pneumonia: clinicopathologic review of a series of 45 Korean patients including rapidly progressive form. J Korean Med Sci 2002;17(2):179-186

40 Lazor R, Vandevenne A, Pelletier A, Leclerc P, Court-Fortune I, Cordier JF. Cryptogenic organizing pneumonia. Characteristics of relapses in a series of 48 patients. The Groupe d'Etudes et de Recherche sur les Maladles "Orphelines" Pulmonaires (GERM"O"P). Am J Respir Crit Care Med 2000;162(2 Pt 1):571-577

41 Lohr RH, Boland BJ, Douglas WW, et al. Organizing pneumonia. Features and prognosis of cryptogenic, secondary, and focal variants. Arch Intern Med 1997;157(12):1323-1329

42 Katzenstein AL, Myers JL, Prophet WD, Corley LS III, Shin MS. Bronchiolitis obliterans and usual interstitial pneumonia. A comparative clinicopathologic study. Am J Surg Pathol 1986; 10(6):373-381

43 Yamamoto M, Ina Y, Kitaichi M, Harasawa M, Tamura M. Clinical features of BOOP in Japan. Chest 1992;102(1, Suppl):21S-25S

44 Alasaly K, Muller N, Ostrow DN, Champion P, FitzGerald JM. Cryptogenic organizing pneumonia. A report of 25 cases and a review of the literature. Medicine (Baltimore) 1995;74(4):201-211

45 Dür P, Vogt P, Russi E. Bronchiolitis obliterans organizing pneumonia (BOOP)-chronic organized pneumonia (COP). Diagnosis, therapy and course [in German]. Schweiz Med Wochenschr 1993;123(29):1429-1438

46 Miyagawa Y, Nagata N, Shigematsu N. Clinicopathological study of migratory lung infiltrates. Thorax 1991;46(4):233-238

47 Costabel U, Teschler H, Schoenfeld B, et al. BOOP in Europe. Chest 1992;102(1, Suppl):14S-20S

48 King TE Jr, Mortenson RL. Cryptogenic organizing pneumonitis. The North American experience. Chest 1992;102(1, Suppl):8S-13S

49 Moreau L, Quoix E, Vandevenne A, et al. Bronchiolitis obliterans with organizing pneumonia. Retrospective study of 19 cases [in French]. Rev Pneumol Clin 1998;54(3):136-143

50 Boots RJ, McEvoy JD, Mowat P, Le Fevre I. Bronchiolitis obliterans organising pneumonia: a clinical and radiological review. Aust N Z J Med 1995;25(2):140-145

51 Chee CB, Da Costa JL, Sim CS. A female with dry cough, progressive dyspnoea and weight loss. Eur Respir J 2005;25(1):206-209

52 Barroso E, Hernandez L, Gil J, Garcia R, Aranda I, Romero S. Idiopathic organizing pneumonia: a relapsing disease. 19 years of experience in a hospital setting. Respiration 2007;74(6):624-631

53 Inoue T, Toyoshima K, Kikui M. Idiopathic bronchiolitis obliterans organizing pneumonia (idiopathic BOOP) in childhood. Pediatr Pulmonol 1996;22(1):67-72

54 Spiteri MA, Klenerman P, Sheppard MN, Padley S, Clark TJ, Newman-Taylor A. Seasonal cryptogenic organising pneumonia with biochemical cholestasis: a new clinical entity. Lancet 1992; 340(8814):281-284

55 Yigla M, Ben-Itzhak O, Solomonov A, Guralnik L, Oren I. Recurrent, self-limited, menstrual-associated bronchiolitis obliterans organizing pneumonia. Chest 2000;118(1):253-256
56 Mroz BJ, Sexauer WP, Meade A, Balsara G. Hemoptysis as the presenting symptom in bronchiolitis obliterans organizing pneumonia. Chest 1997;111(6):1775-1778

57 Iwanaga T, Hirota T, Ikeda T. Air leak syndrome as one of the manifestations of bronchiolitis obliterans organizing pneumonia. Intern Med 2000;39(2):163-165

58 Yang DG, Kim KD, Shin DH, Choe KO, Kim SK, Lee WY. Idiopathic bronchiolitis obliterans with organizing pneumonia presenting with spontaneous hydropneumothorax and solitary pulmonary nodule. Respirology 1999;4(3):267-270

59 Henriet AC, Diot E, Marchand-Adam S, et al. Organising pneumonia can be the inaugural manifestation in connective tissue diseases, including Sjogren's syndrome. Eur Respir Rev 2010; 19(116):161-163

60 Lee JW, Lee KS, Lee HY, et al. Cryptogenic organizing pneumonia: serial high-resolution CT findings in 22 patients. AJR Am J Roentgenol 2010;195(4):916-922

61 Arakawa H, Kurihara Y, Niimi H, Nakajima Y, Johkoh T, Nakamura $\mathrm{H}$. Bronchiolitis obliterans with organizing pneumonia versus chronic eosinophilic pneumonia: high-resolution CT findings in 81 patients. AJR Am J Roentgenol 2001;176(4):1053-1058

62 Roberton BJ, Hansell DM. Organizing pneumonia: a kaleidoscope of concepts and morphologies. Eur Radiol 2011;21(11): 2244-2254

63 Johkoh T, Müller NL, Cartier Y, et al. Idiopathic interstitial pneumonias: diagnostic accuracy of thin-section CT in 129 patients. Radiology 1999;211(2):555-560

64 Norman D, Piecyk M, Roberts DH. Eosinophilic pneumonia as an initial manifestation of rheumatoid arthritis. Chest 2004; 126(3):993-995

65 Hashemzadeh A, Clavel M, Musso C, Touraine F, Paraf F, Bonnaud F. Pseudoneoplastic forms of bronchiolitis obliterans with organizing pneumopathy (BOOP) [in French]. Rev Mal Respir 2001;18 (2):205-208

66 Wagner AL, Szabunio M, Hazlett KS, Wagner SG. Radiologic manifestations of round pneumonia in adults. AJR Am J Roentgenol 1998;170(3):723-726

67 Maldonado F, Daniels CE, Hoffman EA, Yi ES, Ryu JH. Focal organizing pneumonia on surgical lung biopsy: causes, clinicoradiologic features, and outcomes. Chest 2007;132(5):1579-1583

68 Price J. Round pneumonia and focal organizing pneumonia are different entities. AJR Am J Roentgenol 1999;172(2):549-550

69 Astudillo L, Martin-Blondel G, Sans N, Dhaste G, Couret B, ArletSuau E. Solitary nodular form of bronchiolitis obliterans organizing pneumonia. Am J Med 2004;117(11):887-888

70 Ujita M, Renzoni EA, Veeraraghavan S, Wells AU, Hansell DM. Organizing pneumonia: perilobular pattern at thin-section CT. Radiology 2004;232(3):757-761

71 Katzenstein AL, Fiorelli RF. Nonspecific interstitial pneumonia/ fibrosis. Histologic features and clinical significance. Am J Surg Pathol 1994;18(2):136-147

72 Travis WD, Matsui K, Moss J, Ferrans VJ. Idiopathic nonspecific interstitial pneumonia: prognostic significance of cellular and fibrosing patterns: survival comparison with usual interstitial pneumonia and desquamative interstitial pneumonia. Am J Surg Pathol 2000;24(1):19-33

73 Oikonomou A, Hansell DM. Organizing pneumonia: the many morphological faces. Eur Radiol 2002;12(6):1486-1496

$74 \mathrm{Kim}$ SJ, Lee KS, Ryu YH, et al. Reversed halo sign on highresolution $\mathrm{CT}$ of cryptogenic organizing pneumonia: diagnostic implications. AJR Am J Roentgenol 2003;180(5):1251-1254

75 Maimon N. A 47-year-old female with shortness of breath and "reversed halo sign". Eur Respir Rev 2010;19(115):83-85

76 Gudavalli R, Diaz-Guzman E, Arrossi AV, Chapman JT, Mehta AC. Fleeting alveolar infiltrates and reversed halo sign in patients with breast cancer treated with tangential beam irradiation. Chest 2011;139(2):454-459 
77 Marchiori E, Zanetti G, Irion KL, et al. Reversed halo sign in active pulmonary tuberculosis: criteria for differentiation from cryptogenic organizing pneumonia. AJR Am J Roentgenol 2011;197 (6):1324-1327

78 Cordier JF, Cottin V. Eosinophilic pneumonias. In: Schwarz MI, King TE Jr, eds. Interstitial Lung Disease. 5th ed. Shelton, CT: People's Medical Publishing House-USA; 2011:833-893

79 Cottin V. Idiopathic eosinophilic pneumonias. Eur Respir Mon 2011;54:118-139

80 Carrington CB, Addington WW, Goff AM, et al. Chronic eosinophilic pneumonia. N Engl J Med 1969;280(15):787-798

81 Trisolini R, Dallari R, Cancellieri A, Poletti V. Bronchiolitis obliterans organizing pneumonia associated with lower respiratory tract infection by respiratory syncytial virus in an immunocompetent adult. Sarcoidosis Vasc Diffuse Lung Dis 2002;19(3):234-235

82 Sheehan RE, English J, Wittmann R, Müller NL. Levitating consolidation in eosinophilic lung disease. J Thorac Imaging 2003;18 (1):45-47

83 Cordier JF. Cryptogenic organizing pneumonitis. Bronchiolitis obliterans organizing pneumonia. Clin Chest Med 1993;14(4): 677-692

84 Barbato A, Panizzolo C, D’Amore ES, La Rosa M, Saetta M. Bronchiolitis obliterans organizing pneumonia (BOOP) in a child with mild-to-moderate asthma: evidence of mast cell and eosinophil recruitment in lung specimens. Pediatr Pulmonol 2001; 31(5):394-397

85 Kelkel E, Brambilla E, Pison C, et al. Bronchiolitis obliterans with idiopathic organized pneumonia: anatomoclinical analysis and nosologic discussion apropos of 6 cases [in French]. Ann Med Interne (Paris) 1990;141(8):661-667

86 Bellomo R, Finlay M, McLaughlin P, Tai E. Clinical spectrum of cryptogenic organising pneumonitis. Thorax 1991;46(8): 554-558

87 Rees JH, Woodhead MA, Sheppard MN, du Bois RM. Rheumatoid arthritis and cryptogenic organising pneumonitis. Respir Med 1991;85(3):243-246

88 Patel AR, Shah PC, Rhee HL, Sassoon H, Rao KP. Cyclophosphamide therapy and interstitial pulmonary fibrosis. Cancer 1976; 38(4):1542-1549

89 Naccache JM, Faure O, Loire R, Wiesendanger T, Cordier JF. Severe hypoxemia with orthodeoxia due to right to left shunt in idiopathic bronchiolitis obliterans organizing pneumonia [in French]. Rev Mal Respir 2000;17(1):113-116

90 Izumi T, Kitaichi M, Nishimura K, Nagai S. Bronchiolitis obliterans organizing pneumonia: clinical features and differential diagnosis. Chest 1992;102(3):715-719

91 Costabel U, Teschler H, Guzman J. Bronchiolitis obliterans organizing pneumonia (BOOP): the cytological and immunocytological profile of bronchoalveolar lavage. Eur Respir J 1992;5(7): 791-797

92 Poletti V, Cazzato S, Minicuci N, Zompatori M, Burzi M, Schiattone ML. The diagnostic value of bronchoalveolar lavage and transbronchial lung biopsy in cryptogenic organizing pneumonia. Eur Respir J 1996;9(12):2513-2516

93 Nagai S, Aung H, Tanaka S, et al. Bronchoalveolar lavage cell findings in patients with BOOP and related diseases. Chest 1992;102(1, Suppl):32S-37S

94 Jara-Palomares L, Gomez-Izquierdo L, Gonzalez-Vergara D, et al. Utility of high-resolution computed tomography and BAL in cryptogenic organizing pneumonia. Respir Med 2010; 104(11):1706-1711

95 Flowers JR, Clunie G, Burke M, Constant O. Bronchiolitis obliterans organizing pneumonia: the clinical and radiological features of seven cases and a review of the literature. Clin Radiol 1992;45 (6):371-377

96 Azzam ZS, Bentur L, Rubin AH, Ben-Izhak O, Alroy G. Bronchiolitis obliterans organizing pneumonia. Diagnosis by transbronchial biopsy. Chest 1993;104(6):1899-1901
97 Dina R, Sheppard MN. The histological diagnosis of clinically documented cases of cryptogenic organizing pneumonia: diagnostic features in transbronchial biopsies. Histopathology 1993;23(6):541-545

98 Metzger F, Pernet D, Manzoni P, Ranfaing E, Dalphin JC. The contribution of CT-guided transthoracic lung biopsy to the diagnosis of organizing pneumonia [in French]. Rev Mal Respir 2008;25(5):539-550

99 Doxtader EE, Mukhopadhyay S, Katzenstein AL. Core needle biopsy in benign lung lesions: pathologic findings in 159 cases. Hum Pathol 2010;41(11):1530-1535

100 Yebra M, Romero Y, Varela A, Berrocal E. Percutaneous lung biopsy in the diagnosis of bronchiolitis obliterans organizing pneumonia. Chest 1994;105(3):972-973

101 Poulou LS, Tsangaridou I, Filippoussis P, Sidiropoulou N, Apostolopoulou S, Thanos L. Feasibility of CT-guided percutaneous needle biopsy in early diagnosis of BOOP. Cardiovasc Intervent Radiol 2008;31(5):1003-1007

102 Colby TV. Pathologic aspects of bronchiolitis obliterans organizing pneumonia. Chest 1992;102(1, Suppl):38S-43S

103 Kitaichi M. Differential diagnosis of bronchiolitis obliterans organizing pneumonia. Chest 1992;102(1, Suppl):44S-49S

104 Beasley MB, Franks TJ, Galvin JR, Gochuico B, Travis WD. Acute fibrinous and organizing pneumonia: a histological pattern of lung injury and possible variant of diffuse alveolar damage. Arch Pathol Lab Med 2002;126(9):1064-1070

105 Ranzani OT, Parra ER, de Morais Fernezlian S, Capelozzi VL. Intraluminal plugs in idiopathic and secondary organizing pneumonia: repair or remodelling? Histopathology 2007;51(5): 622-630

106 Basset F, Ferrans VJ, Soler P, Takemura T, Fukuda Y, Crystal RG. Intraluminal fibrosis in interstitial lung disorders. Am J Pathol 1986;122(3):443-461

107 Mark EJ, Matsubara O, Tan-Liu NS, Fienberg R. The pulmonary biopsy in the early diagnosis of Wegener's (pathergic) granulomatosis: a study based on 35 open lung biopsies. Hum Pathol 1988;19(9):1065-1071

108 Travis WD, Hoffman GS, Leavitt RY, Pass HI, Fauci AS. Surgical pathology of the lung in Wegener's granulomatosis. Review of 87 open lung biopsies from 67 patients. Am J Surg Pathol 1991; 15(4):315-333

109 Uner AH, Rozum-Slota B, Katzenstein AL. Bronchiolitis obliteransorganizing pneumonia (BOOP)-like variant of Wegener's granulomatosis: a clinicopathologic study of 16 cases. Am J Surg Pathol 1996;20(7):794-801

110 Kawanami O, Basset F, Barrios R, Lacronique JG, Ferrans VJ, Crystal RG. Hypersensitivity pneumonitis in man: light- and electronmicroscopic studies of 18 lung biopsies. Am J Pathol 1983; 110(3):275-289

111 Ito T, Sugino K, Satoh D, et al. Bird fancier's lung which developed in a pigeon breeder presenting organizing pneumonia. Intern Med 2010;49(23):2605-2608

112 Häusler M, Meilicke R, Biesterfeld S, Kentrup H, Friedrichs F, Kusenbach G. Bronchiolitis obliterans organizing pneumonia: a distinct pulmonary complication in cystic fibrosis. Respiration 2000;67(3):316-319

113 Fujimoto K, Müller NL, Kato S, et al. Pneumoconiosis in rush mat workers exposed to clay dye "sendo" dust: clinical, radiologic, and histopathologic features in seven patients. Chest 2004; 125(2):737-743

114 Sison RF, Hruban RH, Moore GW, Kuhlman JE, Wheeler PS, Hutchins GM. Pulmonary disease associated with pleural "asbestos" plaques. Chest 1989;95(4):831-835

115 Cheng T-H, Ko F-C, Chang J-L, Wu K-A. Bronchiolitis obliterans organizing pneumonia due to titanium nanoparticles in paint. Ann Thorac Surg 2012;93(2):666-669

116 Sheu BF, Lee CC, Young YR, Li LF, Chang SS. Delayed-onset bronchiolitis obliterans with organising pneumonia associated 
with massive acetic acid steam inhalation. Thorax 2008; 63(6):570

117 Drakopanagiotakis F, Paschalaki K, Abu-Hijleh M, et al. Cryptogenic and secondary organizing pneumonia: clinical presentation, radiographic findings, treatment response, and prognosis. Chest 2011;139(4):893-900

118 Sveinsson OA, Isaksson HJ, Sigvaldason A, Yngvason F, Aspelund T, Gudmundsson G. Clinical features in secondary and cryptogenic organising pneumonia. Int J Tuberc Lung Dis 2007;11(6):689-694

119 Cottin V, Bonniaud P. Drug-induced infiltrative lung disease. Eur Respir Mon 2009;46:287-318

120 Crestani B, Valeyre D, Roden S, Wallaert B, Dalphin JC, Cordier JF. Bronchiolitis obliterans organizing pneumonia syndrome primed by radiation therapy to the breast. The Groupe d'Etudes et de Recherche sur les Maladies Orphelines Pulmonaires (GERM"O"P). Am J Respir Crit Care Med 1998;158(6):1929-1935

121 Douglas WW, Tazelaar HD, Hartman TE, et al. Polymyositisdermatomyositis-associated interstitial lung disease. Am J Respir Crit Care Med 2001;164(7):1182-1185

122 Cottin V, Thivolet-Béjui F, Reynaud-Gaubert M, et al; Groupe d'Etudes et de Recherche sur les Maladies "Orphelines" Pulmonaires. Interstitial lung disease in amyopathic dermatomyositis, dermatomyositis and polymyositis. Eur Respir J 2003;22(2):245-250

123 Konsta M, Bournia VK, Alexandrou P, Iliopoulos A. Cryptogenic organizing pneumonia mimicking malignancy in a patient with rheumatoid arthritis. J Rheumatol 2011;38(9):2007-2008

124 Yousem SA, Faber C. Histopathology of aspiration pneumonia not associated with food or other particulate matter: a clinicopathologic study of 10 cases diagnosed on biopsy. Am J Surg Pathol 2011;35(3):426-431

125 Foley SC, Préfontaine D, Hamid Q. Images in allergy and immunology: role of eosinophils in airway remodeling. J Allergy Clin Immunol 2007;119(6):1563-1566

126 Yousem SA, Lohr RH, Colby TV. Idiopathic bronchiolitis obliterans organizing pneumonia/cryptogenic organizing pneumonia with unfavorable outcome: pathologic predictors. Mod Pathol 1997; 10(9):864-871

127 Lee JS, Lynch DA, Sharma S, Brown KK, Müller NL. Organizing pneumonia: prognostic implication of high-resolution computed tomography features. J Comput Assist Tomogr 2003;27(2):260-265

128 Oymak FS, Demirbaş HM, Mavili E, et al. Bronchiolitis obliterans organizing pneumonia. Clinical and roentgenological features in 26 cases. Respiration 2005;72(3):254-262

129 Epler GR. Bronchiolitis obliterans organizing pneumonia, 25 years: a variety of causes, but what are the treatment options? Expert Rev Respir Med 2011;5(3):353-361

130 Melloni G, Cremona G, Bandiera A, et al. Localized organizing pneumonia: report of 21 cases. Ann Thorac Surg 2007;83(6): 1946-1951

131 Basarakodu KR, Aronow WS, Nair CK, et al. Differences in treatment and in outcomes between idiopathic and secondary forms of organizing pneumonia. Am J Ther 2007;14(5):422-426
132 Purcell IF, Bourke SJ, Marshall SM. Cyclophosphamide in severe steroid-resistant bronchiolitis obliterans organizing pneumonia. Respir Med 1997;91(3):175-177

133 Watanabe K, Senju S, Wen FQ, Shirakusa T, Maeda F, Yoshida M. Factors related to the relapse of bronchiolitis obliterans organizing pneumonia. Chest 1998;114(6):1599-1606

134 Stover DE, Mangino D. Macrolides: a treatment alternative for bronchiolitis obliterans organizing pneumonia? Chest 2005; 128(5):3611-3617

135 Kastelik JA, Greenstone M, McGivern DV, Morice AH. Cryptogenic organising pneumonia. Eur Respir J 2006;28(6):1291

136 Ichikawa Y, Ninomiya H, Katsuki M, Hotta M, Tanaka M, Oizumi K. Low-dose/long-term erythromycin for treatment of bronchiolitis obliterans organizing pneumonia (BOOP). Kurume Med J 1993; 40(2):65-67

137 Radzikowska E, Wiatr E, Gawryluk D, et al. Organizing pneumonia -clarithromycin treatment [in Polish]. Pneumonol Alergol Pol 2008;76(5):334-339

138 Lee J, Cha SI, Park TI, Park JY, Jung TH, Kim CH. Adjunctive effects of cyclosporine and macrolide in rapidly progressive cryptogenic organizing pneumonia with no prompt response to steroid. Intern Med 2011;50(5):475-479

139 Chang WJ, Lee EJ, Lee SY, et al. Successful salvage treatment of steroid-refractory bronchiolar COP with low-dose macrolides. Pathol Int 2012;62(2):144-148

140 Cohen AJ, King TE Jr, Downey GP. Rapidly progressive bronchiolitis obliterans with organizing pneumonia. Am J Respir Crit Care Med 1994;149(6):1670-1675

141 Churg A, Wright JL, Tazelaar HD. Acute exacerbations of fibrotic interstitial lung disease. Histopathology 2011;58(4): 525-530

142 Nagai S, Kitaichi M, Itoh H, Nishimura K, Izumi T, Colby TV. Idiopathic nonspecific interstitial pneumonia/fibrosis: comparison with idiopathic pulmonary fibrosis and BOOP. Eur Respir J 1998;12(5):1010-1019

143 Kobayashi H, Sugimoto C, Kanoh S, Motoyoshi K, Aida S. Acute fibrinous and organizing pneumonia: initial presentation as a solitary nodule. J Thorac Imaging 2005;20(4):291293

144 de Carvalho M-EP, Kairalla RA, Capelozzi VL, Deheinzelin D, do Nascimento Saldiva PH, de Carvalho CRR. Centrilobular fibrosis: a novel histological pattern of idiopathic interstitial pneumonia. Pathol Res Pract 2002;198(9):577-583

145 Mark EJ, Ruangchira-urai R. Bronchiolitis interstitial pneumonitis: a pathologic study of 31 lung biopsies with features intermediate between bronchiolitis obliterans organizing pneumonia and usual interstitial pneumonitis, with clinical correlation. Ann Diagn Pathol 2008;12(3):171-180

146 Thivolet F, Loire R, Cordier JF. Bronchiolitis with peribronchiolar organizing pneumonia (B-POP): a new clinicopathologic entity in bronchiolar/interstitial lung disease? [abstract]. Eur Respir J 1999; $14: 272 s$ 